\title{
NEUROPSYCHOMOTOR DEVELOPMENT BEFORE AND AFTER OPEN-HEART SURGERY IN INFANTS
}

\author{
Taís Sica da Rocha', Ana Guardiola², Jefferson Pedro Piva, \\ Cláudia Pires Ricachinevski ${ }^{4}$, Aldemir Nogueira ${ }^{5}$
}

\begin{abstract}
There are few Brazilian studies on neuropsychomotor follow-up after open-heart surgery with circulatory bypass in infants. Twenthy infants had neurodevelopmental outcomes (neurological exam and Denver II test) assessed before open-heart surgery, after intensive care unit discharge and 3-6 months after hospital discharge. Heart lesions consisted of septal defects in 11 cases (55\%). The mean circulatory bypass time was $67 \pm 23.6$ minutes. Fifteen infants had altered neurological examination and also neurodevelopment delay before surgery. After 6 months it was observed normalization in 6 infants. When Denver II test indexes were analysed, it was observed an improvement in all domains except personal-social. Although those infants were in risk of new neurological findings, an early improvement on neuropsychomotor indexes were seen.
\end{abstract}

KEY WORDS: cardiac surgery, developmental delay, Denver II test.

\section{Desenvolvimento neuropsicomotor de lactentes antes e após cirurgia cardíaca}

Resumo - As alterações neurológicas em lactentes com cardiopatia congênita podem agravar seu quadro clínico e levar a seqüelas permanentes. Foi realizada uma coorte prospectiva, com 20 lactentes, com idade média de 6,7 $\pm 4,2$ meses, avaliando-se o perfil de desenvolvimento e o estado nutricional. Utilizou-se o exame neurológico e o teste de Denver II. Os testes foram aplicados $24 \mathrm{~h}$ antes da cirurgia, na alta da unidade de terapia intensiva e 3 a 6 meses após. Os defeitos septais ocorreram em 11 casos (55\%). O tempo médio de circulação extra-corpórea foi de 67ffl23,6 minutos. Quinze crianças tinham exame neurológico alterado e atraso no desenvolvimento neuropsicomotor antes da cirurgia, cuja normalização foi observada somente em seis após 6 meses.Quanto aos índices de Denver II, houve aumento em todos domínios, exceto o pessoalsocial. O escore $Z$ médio para peso antes da cirurgia foi $-2,814 \pm 1,98$ e após $-1,08 \pm 1,47$ ( $p<0.05)$, o qual foi realizado em média $5.2 \pm 1.5$ meses após a alta hospitalar. Melhora precoce tanto no desenvolvimento como no estado nutricional pôde ser observada neste grupo de lactentes após a correção cirúrgica.

PALAVRAS-CHAVE: cirurgia cardiaca, atraso no desenvolvimento neurológico, teste de Denver II, cardiopatia congênita.

Corrective cardiac surgery involves a series of complex and high risk procedures and a large number of them expose the brain to hypoxic ischemic insults ${ }^{1}$. Prospective studies have shown that $100 \%$ of children who undergo cardiac surgery present with central nervous system dysfunctions in the immediate post-operative period ${ }^{2}$ as a consequence of alterations in the cerebral blood flow. If the hypoxic ischemic insult is acute and extensive, the patients may not regain consciousness in the immediate post-operative period and stand increased chances of irreversible sequelae. Some of the neurological findings that may be observed are seizures, alterations of consciousness, behavioral disorders, intellectual impairment, focal deficit, involuntary movements, and lesions to the periph-

\footnotetext{
'Intensivista Pediátrico do Hospital da Criança Santo Antônio - Complexo Hospitalar Santa Casa de Porto Alegre, Porto Alegre RS, Brazil. Mestre em Ciências Médicas, Pediatria Universidade Federal do Rio Grande do Sul, Porto Alegre RS, Brazil; ${ }^{2}$ Neurologista Pediátrica, Professora Adjunta da Universidade Federal de Ciências da Saúde de Porto Alegre, Porto Alegre RS, Brazil; ${ }^{3}$ Intensivista Pediátrico, Professor Adjunto da Universidade do Rio Grande do Sul, Porto Alegre RS, Brazil; ${ }^{4}$ Intensivista Pediátrico da Unidade de Terapia Intensiva do Hospital da Criança Santo Antônio - Complexo Hospitalar Santa Casa de Porto Alegre, Porto Alegre RS, Brazil; ${ }^{5}$ Cirurgião Cardíaco Pediátrico, Serviço de Cirurgia Cardíaca do Complexo Hospitalar Santa Casa de Porto Alegre, Porto Alegre RS, Brazil.
}

Received 25 September 2008, received in final form 5 January 2009. Accepted 26 March 2009.

Dra. Taís Sica da Rocha - Rua Farias Santos 500/301 - 90670-150 Porto Alegre RS - Brasil. E-mail: darochats@hotmail.com 
eral nervous system. Recent studies have assessed the influence of diverse circulatory bypass techniques on the neuropsychomotor development of newborns with transposition of the great arteries ${ }^{1-6}$. More recently, the repercussions of circulatory bypass and moderate hypothermia for the correction of common defects, such as septal defects and tetralogy of Fallot, have been studied ${ }^{7-10}$. It is known that infants with congenital heart disease have low weight gain ${ }^{11-20}$. After the surgery, nutritional development is restored. The positive relation between nutritional status and delayed psychomotor development was only determined in preschoolers years after the surgery ${ }^{18}$.

Breakthroughs in diagnosis, in early indications, as well as in the field of cardiac surgery and post-operative care result in increased survival rates among patients with congenital heart disease. These children often develop neurological alterations brought on by pre-operative, transoperative and post-operative factors. Such neurological complications may aggravate the patientsi clinical condition and subsequently their prognoses; hence the importance of their investigation in order to avoid sequelae ${ }^{21}$.

This study was carried out in order to assess the impact of cardiac surgery on the nutritional status and psychomotor and neurodevelopment in infants who underwent circulatory bypass with moderate hypothermia after 6 months from surgery performed before 24 months of age.

\section{METHOD}

A prospective series of cases was carried out with cardiac surgery patients who were consecutively admitted at the pediatric intensive care unit (ICU) of the Hospital da Criança Santo Antônio, which integrates the Complexo Hospitalar Santa Casa in Porto Alegre.

\section{Sample}

All patients aged 1 month to 2 years who underwent cardiac surgery with circulatory bypass and were admitted consecutively in the period between April 2001 and September 2002 were included in this study. Patients with a history of prior severe neurological disease, seizures or the use of anticonvulsant drugs were excluded.

All the patients were operated on by the same surgical and postoperative care team.

\section{Instruments}

Neurological assessment - The neurological assessment was performed by a pediatric neurologist at the patientis hospitalization for the surgery, at discharge from the ICU and again between 3 and 6 months from postoperative period.

The neurological assessment consists of a neurological anamnesis $^{22}$ and a neurological examination ${ }^{23,24}$. The latter evaluates the following items: behavioral status, attitude, static balance, dynamic balance, fine motor skills, gross motor skills, strength, coordination, muscle tone, automatic movement, involuntary movement, myotatic reflex, exteroceptive reflex, primitive reflex activity, sensitivity, cranial nerves, spinal cord, rigidity of the nape and skull (head, biauricular and antero-posterior breadths and fontanelles) ${ }^{23}$. Additionally, a neurodevelopment examination was conducted in order to evaluate the evolution profile of motor skills, posture, praxic and gnostic functioning as well as sociability and language ${ }^{23-25}$. After admission to the ICU, the parents of the patients with neurological alterations were advised to stimulate their children and forward them to physical therapy.

At each assessment, the neurologist offered a global conclusion by defining the examination as normal, when both the classical neurological examination and the development profile were normal, or as altered, when there was at least one alteration in both the examination and the profile.

Denver II test - Neuropsychomotor development was also assessed using the Denver II, which was applied by two blind independent pediatricians. The agreement between the examiners regarding the total assessed items on the test varied between 89 and $100 \%$.

Two interpretations of the test were used. The first was in accordance with the manual criteria ${ }^{26}$ for normal and suspicion of delay. The second took into account the tasks fulfilled successfully and those deemed compulsory according to the age of the patient. Compulsory tasks were those whose age was above the 90 percentile. Achievement percentage was calculated by dividing the number of successful tasks by that of compulsory tasks. This achievement percentage was named the Denver II score and was calculated for each domain of the test.

\section{Ethics}

The study was approved by the Ethics Committee of the Complexo Hospitalar Santa Casa de Porto Alegre and parents signed the informed consent.

\section{Logistics}

The first neurological assessment and that of neuropsychomotor development were carried out a day before the surgery by the neurologist and by the pediatrician, respectively.

The children were followed up for the full length of their stay at the hospital in search of complications related to the surgical procedure or neurological complications.

Thus, each individual had a protocol containing the studied variables, the Denver II test protocol and the standardized ambulatory protocol.

\section{Variables of interest}

The variables of interest were categorized as follows: related to the heart disease: type of defect (cyanotic and acyanotic); age and weight on the day of the surgery; weight $Z$ score; related to the transoperative period: degree of hypothermia; bypass and aortic clamping time. 


\section{Statistical analysis and data processing}

The descriptive variables were presented in percentages, averages, standard deviations, means and amplitudes.

Mc Nemaris Chi-square test was used for the comparison of the categorical variables between groups: normal $\times$ delayed, $c y-$ anotic $\times$ acyanotic.

The t-Student test was used to compare the pre and post surgical means for the Denver II scores, adaptive and gross motor skills, language and personal-social domains, as well as for the Z score.

The $t$ test was used for the comparison between the means of several variables (length of ICU stay and circulatory bypass and clamping time) between normal and delayed infants.

The $\mathrm{Z}$ score was calculated using NCHS data.

The SPSS 10.0 for Windows was used for all statistical analyses.

\section{RESULTS}

Initially, 25 children aged $6.7 \pm 4.2$ months and with a mean weight of $5.3 \pm 2.2 \mathrm{~kg}$ (Table 1) were included in the study. There were 5 deaths after the surgery.

Approximately $40 \%$ (8) of the cardiac surgeries were performed on children with cyanotic heart diseases. The septal defects present in 11 of 20 patients were the most frequent (Table 2).

Four $(20 \%)$ children required surgical re-intervention while still in the ICU. Six patients had other complications such as ectopic junctional tachycardia, total atrioventricular block, quilothorax, atelectasis, bronchopneumonia (2 patients) and pneumothorax. Seven (35\%) patients had to be readmitted to the hospital within the 6 month period between the first and the last assessment, yet not due to cardiac problems.

The neurological examination performed at ICU discharge took place on average on the $13.4 \pm 7.6$ day of hospitalization. When comparing the preoperative neurological exams and those at ICU discharge no changes were found in 19 patients (95\%), whereas 1 child demonstrated recovery. The ambulatory reassessment of the neurological examination was conducted on average at 5.2 \pm 1.5 months after hospital discharge ( 3 to 8 months). Six out of the 15 patients considered clearly delayed in the neurologistís initial examination had normal outcomes $(p=0.03)$ (Table 3). When comparing the pre-operative and ambulatory assessments regarding the prevalence of suspicion of delay as defined by the Denver II test a reduction of suspect cases from $75 \%$ to $55 \%(p=0.12)$ was found.

The average $\mathrm{Z}$ score for weight prior to the surgery was of $-2.814 \pm 1.98$ and of $-1.08 \pm 1.47(p=0.0000)$ after it, also conducted on average at $5.2 \pm 1.5$ months after hospital discharge,proving significant improvement of these patientsi nutritional status after the correction.

In addition, it was found that there was an associa-
Table 1. General characteristics.

\begin{tabular}{lc}
\hline Variable & Value \\
\hline General data & \\
Age $( \pm s d)$ in months & $6.7 \pm 4.2$ \\
Median [range] & $6[1-19]$ \\
Weight $( \pm \mathrm{sd})$ in Kg & $5.3 \pm 2.2$ \\
$\quad$ Median [range] & $4.6[2.4-11]$ \\
$\quad$ Severe malnutrition (z score $\leq-3)(\%)$ & $15(75)$ \\
Trans-operative variables & \\
CBP time ( \pm sd) in minutes & $67 \pm 23.6$ \\
$\quad$ Median [range] & $65[39-105]$ \\
Clamping time $( \pm s d)$ in minutes & $34.1 \pm 16$ \\
$\quad$ Median [range] & $34[0-56]$ \\
Post-operative variables & \\
Surgical re-intervention (\%) & $4(20)$ \\
Complications in the ICU (\%) & $6(30)$ \\
Length of ICU stay ( $\pm s d)$ in days & $13.4 \pm 7.6$ \\
$\quad$ Median [range] & $10.5[7-29]$ \\
\hline
\end{tabular}

${ }^{*}$ Data expressed as mean \pm standard deviation, median; ICU: intensive care unit; CBP: circulatory bypass; [min-max] or number (\%) of patients.

Table 2. Distribution of cardiac defects.

\begin{tabular}{llcc}
\hline & Cardiac defect & N & $\%$ \\
\hline \multirow{4}{*}{ Non-cyanotic } & Ventricular septal defect (VSD) & 5 & 25 \\
& Atrioventricular septal defect & 5 & 25 \\
& Shone's complex & 1 & 5 \\
& Aortic stenosis with VSD & 1 & 5 \\
& Fallot's tetralogy & 2 & 10 \\
& Total anomalous pulmonary & & \\
Cyanotic & venous return & 2 & 10 \\
& Pulmonary atresia with VSD & 1 & 5 \\
& Pulmonary stenosis with VSD & 1 & 5 \\
& Atrial septal defect with & 1 & 5 \\
& pulmonary stenosis & & \\
& Truncus ateriosus type I & 1 & 5 \\
& Total & 20 & 100 \\
\hline
\end{tabular}

Table 3. Pre-operative, postoperative and outpatient neurodevelopment by pediatric neurologist.

\begin{tabular}{lccc}
\hline \multicolumn{4}{c}{ Neurodevelopment evaluation by pediatric neurologist } \\
\hline & $\begin{array}{c}\text { Pre-operative* } \\
\text { (n) }\end{array}$ & $\begin{array}{c}\text { Postoperative } \\
\text { (n) }\end{array}$ & $\begin{array}{c}\text { Outpatient* } \\
\text { (n) }\end{array}$ \\
\hline Normal & 5 & 6 & 11 \\
Altered & 15 & 14 & 9 \\
\hline
\end{tabular}

${ }^{*} \chi^{2}$ de Mc Nemar; $p=0.03$

tion between malnutrition (weight $Z$ score $\leq-2$ for age) in the follow-up and delay in development, with a relative risk of 5.25 (IC 95\%; 1.44 to 19.11; $p=0.03$ ). It was also found that there was a positive correlation between the weight $\mathrm{Z}$ score and the Denver II scores in all domains in 
Table 4. Pre-operative and 3 to 6 months after surgery Denver II Score (\%) by pediatricians.

\begin{tabular}{|c|c|c|c|c|c|c|}
\hline & $\begin{array}{c}\text { Mean pre } \pm S D \\
{[\%]^{*}}\end{array}$ & $\begin{array}{c}\text { Mean post } \pm \text { SD } \\
{[\%]^{*}} \\
\end{array}$ & $\begin{array}{c}\text { Difference mean }{ }^{\#}[\%] \\
{[\mathrm{Cl} 95 \%]}\end{array}$ & p value & Effect size & Magnitude \\
\hline Total [\%] & $73.2 \pm 20.5$ & $90.2 \pm 18.4$ & 17.05 [10.85 to 23.25$]$ & .0001 & 1.29 & Large \\
\hline Gross motor [\%] & $67.5 \pm 25.7$ & $83 \pm 19$ & 15.5 [3.51 to 7.5$]$ & 0.014 & 0.6 & Moderate \\
\hline Fine motor [\%] & $76.35 \pm 28.9$ & $92.7 \pm 18.54$ & 16.35 [5.4 to 27.33$]$ & 0.006 & 0.7 & Moderate \\
\hline Language [\%] & $69.6 \pm 25.3$ & $92.9 \pm 23.13$ & 23.35 [17.01 to 29.7] & .0000 & 1.722 & Large \\
\hline Personal-social [\%] & $82.9 \pm 25.6$ & $92.1 \pm 20.5$ & 9 [2 to 20.4$]$ & 0.105 & 0.38 & Small \\
\hline
\end{tabular}

*Mean pre: mean score of sample before surgery; Mean post: mean score 3 to 6 months after surgery; ${ }^{\#}$ Mean pre - mean post; 'Student $t$ test.

Table 5. Comparison of Denver II test indexes between cyanotic and non-cyanotic.

\begin{tabular}{lccccc}
\hline Variable & Cyanotic (8) [mean \pm sd] & Non-cyanotic (12) [mean \pm sd] & $p$ value & Effect size & Magnitude \\
\hline Gross motor [\%] & $84 \pm 12,8$ & $82.3 \pm 22.7$ & 0.84 & 0.09 & trivial \\
Language [\%] & $97.6 \pm 17$ & $89.7 \pm 26.3$ & 0.44 & 0.4 & small \\
Fine motor [\%] & $100 \pm 5.8$ & $85.9 \pm 21.1$ & 0.02 & 0.8 & moderate \\
Personal-social [\%] & $91.4 \pm 17.8$ & $92 . . \pm 22.8$ & 0.9 & 0.05 & trivial \\
Total [\%] & $94.6 \pm 13.4$ & $87.2 \pm 20.7$ & 0.35 & 0.4 & small \\
\hline
\end{tabular}

the postoperative period $(p<0.05)$; with correlation coefficient of 0.72 for gross motor and language, 0.62 for fine motor and 0.49 for personal-social,respectively.

The pre-operative value of the Denver II score increased after surgery in all domains except for the personal-social one. The total score (sum of all domains) and the language domain had large effect size magnitude, while the motor domains had moderate magnitude. (Table 4)

When comparing the children whose delay persisted to those considered normal by the neurological examination no difference was found in the following variables: length of ICU stay, age at correction, weight before surgery as well as circulatory bypass and aortic clamping time.

In this sample, we observed only a tendency for all the scores of the Denver II to be more elevated in patients with cyanotic heart disease. However, cyanotic heart disease patients only demonstrated a better performance on fine motor skills (Table 5).

\section{DISCUSSION}

This longitudinal neurodevelopmental follow-up study of infants submitted to cardiac surgery and circulatory bypass, showed: (A) the elevated prevalence of alterations in the neurological and developmental examination found in the pre-operative stage $(75 \%)$ is reduced $(45 \%)$ in the examination conducted on average 5 months afterwards (B) infants acquire further motor and cognitive skills, as verified by the improvement on the Denver II scores (C) nutritional status is also improved (C) no correlation was found between transoperative factors, circulatory bypass and clamping time and development outcomes; (D) children with cyanotic heart diseases had better scores on the adaptive motor domain.

Given the small sample in this study, we were only able to observe differences related to major effects. However, for important variables which may not express such dramatic effects (bypass time, for instance) this sample may have been insufficient to verify effects on development.

The abnormal neurological examination even before the surgery has been described in earlier studies. Delay prevalence is estimated to be at $38 \%{ }^{27}$. In our population it was even higher, reaching $75 \%$ of the children prior to the surgery. The pathology of congenital heart disease is a risk for good neurological performance, which justifies the finding of a high prevalence of children with altered neurological exams prior to the surger $y^{28}$. Infants submitted to cardiac surgery with bypass are a risk population for new findings. The main reasons behind this increased risk are situations which occur during and after the surgery, such as the formation of emboli, hypothermia and loss of cerebral regulation as well as inflammatory and metabolic alterations. In our study, however, a drop from $75 \%$ to $45 \%$ was found in the number of individuals with neurodevelopmental delay between the pre-operative period and at 5 months after the surgery. Nonetheless, the persistence of neurological alterations, even with longer assessment periods between one evaluation and the other is described, being worse in cyanotic patients ${ }^{4}$.

An analysis of the use of the Denver II test on a population of children with heart disease becomes necessary. 
In this population, studies on development usually use psychometric scales. The Denver II test is widely used in triage for delay in the pediatric population from zero to 6 years of age. Denver II results are expressed in terms of the percentage of what is expected based on age, which enables a quantification of the improvement on scores. In the language domain, for instance, there was a mean increase of $23 \%$ on the score before the correction, which may have varied between 17 and 30\% according to the reliability interval calculated for this domain. Another interpretation of the Denver II scores is that it demonstrated a further restoration of development rates at approximately $20 \%$ five months after the surgery in all domains of the test, except for the personal-social one. However, what this means in terms of future development or even whether this rate of development is maintained is yet to be further determined.

It is important to point out the validity of trans-operative and pos-operative measures for neurological outcome. A large number of studies state that bypass time is one of the main factors associated with untoward neurological outcomes, given that the higher the likelihood of embolisms, and deregulation caused by hypothermia, the higher the inflammatory and metabolic activity ${ }^{27}$. Another trans-operative factor that is often cited in the literature is the correction or not of the $\mathrm{pH}$ by the temperature. The use of a more alkaline $\mathrm{pH}$ (alpha-stat not corrected by temperature) has proven to confer lower cerebral protection potential. There is a positive correlation between $\mathrm{pCO}_{2}$ and development scores ${ }^{26}$. When combined with deep hypothermia the alpha-stat strategy plays a protective role in terms of neurological outcomes. There is no evidence yet of this effect when coupled with moderate hypothermia, which was the method used in this study. It must be highlighted that our study was incapable of detecting paroxistic neurological events. Seizures, which are indubitably the most common in the post-operative period, were not found in the individuals who completed the study. The 2 patients who seized died while still in the ICU. Both were diagnosed with associated genetic syndrome, and one of them had obstruction of the aortic arch. There is a correlation between risk of seizures and pre-existing genetic diseases, deep hypothermia with circulatory arrest for over 60 minutes and obstruction of the aortic $\operatorname{arch}^{29}$.

When cyanotic and acyanotic patientsi scores for all the Denver II domains were compared, only a minor difference was found, though contradicting most of the existing literature, cyanotic cases tended to have worse outcomes. Factors such as degree of previous heart insufficiency and degree of cyanosis (in newborns, saturation $<85 \%$ was significantly associated with abnormalities) ${ }^{27}$ could have explained the difference found, yet they were not assessed.
Important situations such as socio-economic level, acidosis and pre-operative hypoxia as well as signs of low post-operative debt, all of which provide for a greater risk of significant future delays, were not assessed ${ }^{6}$.

The proven significance of weight gain in restoring development in post heart-surgery patients at such an early phase of development (under 24 months of age) is an original finding of our study. There are studies in the literature which only assess pre and post weight gain without assessing psychomotor development concomitantly ${ }^{14,16,17}$. There are several theoretical explanations for these findings. Some patients are already born underweight, yet no hemodynamic pattern of fetal circulation was associated with this finding. The fact that congenital heart disease patients have an increased metabolic demand yet a reduced capacity for caloric intake may contribute to their low weight. Endocrinological factors may also be involved; the role of IGF-1 is being studied. Other favorable and unfavorable factors towards the normal development of these children must also be further studied.

Other possible explanations for the childrenis improvement regarding the tasks set are higher tolerance to exercise, enhanced physical capacity, or better interaction with parents, all of which may facilitate performance of the tasks. However, the future of these children may be compromised due to delays before the procedure ${ }^{29}$.

\section{REFERENCES}

1. Arita NF, Diament A. Manifestações neurológicas de doenças sistêmicas. In Diament AJ, Cypel S (Eds). Neurologia infantil. São Paulo: Atheneu, 2005:1553-1577.

2. Steinberg A, Frank Y. Neurological manifestations of systemic diseases in children.In The International Series of Child Neurology. New York: Raven Press, 1993:60-165-202-242-280.

3. Bellinger DC, Wypij D, Kuban KC et al. Developmental and neurological status of children at 4 years of age after heart surgery with hypothermic circulatory arrest or low-flow cardiopulmonary bypass. Circulation 1999;100:526-532.

4. Wray J, Sensky T. Controlled study of preschool development after surgery for congenital heart disease. Arch Dis Child 1999; 80:511-516.

5. Wray J, Sensky T. Congenital heart disease and cardiac surgery in childhood: effects on cognitive function and academic ability. Heart 2001;85:687-691.

6. Hövels-Gürich HH, Seghaye MC, Schnnitker R et al. Longterm neurodevelopment outcomes in school-aged children after neonatal arterial switch operation. J Thorac Cardiovasc Surg 2002;124:448-458

7. Bellinger DC, Wypij D, du Duplessis AJ et al. Neurodevelopmental status at eight years in children with dextro-transposition of the great arteries: the Boston Circulatory Arrest Trial. J Thorac Cardiovasc Surg 2003;126:1385-1396

8. Karl TR, Hall S, Ford G et al. Arterial switch with full-flow car- 
diopulmonary bypass and limited circulatory arrest: neurodevelopmental outcome. J Thorac Cardiovasc Surg 2004;127:213-222

9. Hövels-Gürich HH, Konrad K, Skorzenski D et al. Long-term neurodevelopmental outcome and exercise capacity after corrective surgery for tetralogy of Fallot or ventricular septal defect in infancy. Ann Thorac Surg 2006;81:958-966.

10. Kaltman JR, Jarvik GP, Bernbaum J et al. Neurodevelopmental outcome after early repair of a ventricular septal defect with or without aortic arch obstruction. J Thorac Cardiovasc Surg 2006;131:792-798.

11. Miatton M, De Wolf D, François K, Thiery E, Vingerhoets G. Intellectual, neuropsychological, and behavioral functioning in children with tetralogy of Fallot. J Thorac Cardiovasc Surg 2007;133:449-455.

12. Gaynor JW, Wernovsky G, Jarvik GP et al. Patient characteristics are important determinants of neurodevelopmental outcome at one year of age after neonatal and infant cardiac surgery. J Thorac Cardiovasc Surg 2007;133:1344-1353

13. Mitchell IM, Logan RW, Pollock JC, Jamieson MP. Nutritional status of children with congenital heart disease. Br Heart J 1995;73:277-283.

14. Schuurmans FM, Pulles-Heintzberger CF, Gerver WJ, Kester AD, Forget PP. Long-term growth of children with congenital heart disease: a retrospective study. Acta Paediatr 1998;87:1250-1255.

15. Varan B, Tokel K, Yilmaz G. Malnutrition and growth failure in cyanotic and acyanotic congenital heart disease with and without pulmonary hypertension. Arch Dis Child 1999;81:49-52.

16. Cheung MM, Davis AM, Wilkinson JL, Weintraub RG. Long term somatic growth after repair of tetralogy of Fallot: evidence for restoration of genetic growth potential. Heart 2003;89:1340-1343.

17. Ardura Fernández J, González Herrera C, Aragón García MP. Hemodynamics and delayed growth in children after surgery for atrial septal defect. An Pediatr (Barc) 2003;58:302-308.
18. da Silva VM, de Oliveira Lopes MV, de Araujo TL. Growth and nutritional status of children with congenital heart disease. J Cardiovasc Nurs 2007;22:390-396.

19. Martins da Silva V, de Oliveira Lopes MV, Leite de Araujo T. Evaluation of the growth percentiles of children with congenital heart disease. Rev Lat Am Enfermagem 2007;15: 298-303.

20. Chen CW, Li CY, Wang JK. Growth and development of children with congenital heart disease. J Adv Nurs 2004;47: 260-269.

21. Mahle WT. Neurologic and cognitive outcomes in children with congenital heart disease. Curr Opin Pediatr 2001;13:482-486.

22. Diament A, Cypel S. A anamnese em neurologia infantil. In Diament AJ,CypelS(eds). Neurologia Infantil. São Paulo: Atheneu, 2005:35-66.

23. Diament AJ. Exame neurológico do lactente. In Diament AJ, CypelS(eds). Neurologia Infantil. São Paulo: Atheneu, 2005:35-66.

24. Lefèvre AB. Exame neurológico da criança. In Tolosa APM, Canelas HM (Eds). Propedêutica neurológica. São Paulo: Savier, 1975:376-401.

25. Brunet $\mathrm{O}$, Lézine I. O desenvolvimento psicológico da primeira infância. TRAD. de Ana Guardiola Brizolara. Porto Alegre, Artes Médicas, 1981.

26. Frankenburg WK, Dodds J, Archer P et al. Denver II training manual. $2^{\text {nd }}$ Ed. Denver: DDM materials, 1992.

27. Limperopoulos C, Majnemer A, Shevell MI et al. Neurodevelopmental status of newborns and infants with congenital heart surgery. J Pediatr 2000;137:602-604.

28. Jonas RA, Bellinger DC, Rappaport LA et al. Relation of $\mathrm{pH}$ strategy and development outcome after hypothermic circulatory arrest. J Thorac Cardiovasc Surg 1993;106:326-368.

29. Limperopoulos C, Majnemer A, Shevell MI et al. Functional limitations in young children with congenital heart defects after cardiac surgery. Pediatrics 2001;108:1325-1331. 